\title{
Where is the bigger picture in the teaching and learning of mathematics?
}

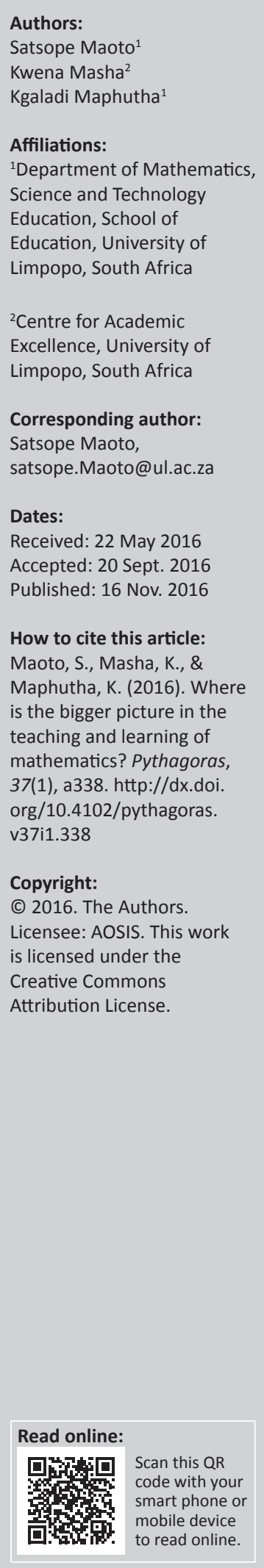

This article presents an interpretive analysis of three different mathematics teaching cases to establish where the bigger picture should lie in the teaching and learning of mathematics. We use pre-existing data collected through pre-observation and post-observation interviews and passive classroom observation undertaken by the third author in two different Grade 11 classes taught by two different teachers at one high school. Another set of data was collected through participant observation of the second author's Year 2 University class. We analyse the presence or absence of the bigger picture, especially, in the teachers' questioning strategies and their approach to content, guided by Tall's framework of three worlds of mathematics, namely the 'conceptual-embodied' world, the 'proceptual-symbolic' world and the 'axiomatic-formal' world. Within this broad framework we acknowledge Pirie and Kieren's notion of folding back towards the attainment of an axiomatic-formal world. We argue that the teaching and learning of mathematics should remain anchored in the bigger picture and, in that way, mathematics is meaningful, accessible, expandable and transferable.

\section{Introduction}

Our major concern in this article lies with pursuing the question: where is the bigger picture in the teaching and learning of mathematics? It is prompted by the kinds of tasks, questions, classroom interactions and targeted content that ground mathematics teaching and learning within and across the different educational levels. In most cases, these teaching and learning activities seem to lack coherence, lack focus on important mathematics and lack appropriate articulation. One of the contributing factors that always affects students' mathematics performance is the fact that a variety of teaching styles are to be found in operation in mathematics lessons, each depending on the teacher's knowledge (skills and attitudes) of mathematics and the teacher's knowledge about teaching mathematics. Hiebert and Grouws (2007) claim that the nature of classroom mathematics teaching significantly affects the nature and level of students' learning. This claim seems obvious, especially as students have different learning styles and for a teacher to produce quality learning requires working well in all learning style modes.

For Tall (2006), success comes from focusing on the most generative ideas, not from covering detail again and again. Thus, if attaining success comes in that manner, it suggests that in teaching or developing any mathematics concept we need to seek out the generative ideas or big ideas (Charles, 2005) that are at the root of more powerful learning. A big idea, as proposed by Charles (2005, p. 10), is 'a statement of an idea that is central to the learning of mathematics, one that links numerous mathematical understandings into a coherent whole'. To some extent Charles's definition of a big idea contributes to our thinking of what and where a bigger picture in the teaching and learning of mathematics is. Big ideas make connections. Good teaching, we argue, should make these connections explicit, meaningful, accessible, expandable and transferable. For each big idea there are mathematical understandings.

Mathematical understandings of a number of different big ideas are important ideas that students need to learn because they contribute to an understanding of the bigger picture of mathematics. This is explained well by Charles (2005), who says that some mathematical understandings of big ideas can be identified through careful content analysis, but many must be identified by hermeneutic listening to students (Davis, 1997), recognising common areas of misconceptions, alternative conceptions or confusion, and analysing issues that underlie those misconceptions, alternative conceptions or confusion. According to Tall (2011), part of a bigger picture is also seeing a student becoming capable of looking at a recurring pattern and seeing many different ways of interpreting and representing it, for example, in words, numerically, algebraically or graphically. 


\section{Purpose of study}

The purpose of the study was to pursue the question: where is the bigger picture in the teaching and learning of Mathematics?

\section{Theoretical framework}

Over the years, researchers have generally defined good mathematics teaching implicitly, with focus on various processes, such as reasoning and problem-solving (Wilson, Cooney \& Stinson, 2005), students' and teachers' explorations, constructing and mathematising (Tarlow, 2014). Rather than a discipline or body of knowledge (concepts, skills) to be transmitted, mathematics is defined from the perspective of 'mathematising': the activity of interpreting, organising and constructing meaning of situations with mathematical modelling or by presenting a notation (Tarlow, 2014). Based on these views, this study is located within a broader framework of what Tall (2008) refers to as three worlds of mathematics: the 'conceptual-embodied' world based on perception, action and thought experiment, the 'proceptualsymbolic' world of calculation and algebraic manipulation and the 'axiomatic-formal' world of set-theoretic concept definitions and mathematical proof. Each 'world' has its own sequence of development and its own forms of proof that may be blended together to give a rich variety of ways of thinking mathematically (Tall, 2008).

Tall's (2008) three worlds of mathematics offers an overview of the process inherent in mathematics and its teaching and learning. However, in this article we take a different line from that of Tall as we interrogate the influence of the bigger picture at the teacher-learner interface. At a higher level from which Tall frames his argument, the impression he gives is that there is sequential progression from the 'conceptual-embodied' world to the 'proceptual-symbolic' world and ultimately to the 'axiomatic-formal' world. While he acknowledges that at the formal-axiomatic world, structure theorems can lead back to worlds of embodiment and symbolism, it is not immediately clear how the process links to teaching activities at classroom level. Our view is underpinned by the earlier position of Gray, Pitta, Pinto and Tall (1999), in which they represented the increasing compression from procedure through multi-procedure, process and procept. That representation clearly shows the sequential developments of mathematical thinking from pre-procedures to procepts. It is here that we found Pirie and Kieren's (1994, p. 69) notion of folding back more appropriate. Their theory of growth in mathematical understanding comprises eight levels, namely primitive knowing, image making, image having, property noticing, formalising, observing, structuring and inventising. Folding back is the process through which mathematical understanding grows through these levels. This is a non-unidirectional process of coming to understand the bigger picture of teaching and learning mathematics. That is 'when faced with a problem or question at any level, which is not immediately solvable, one needs to fold back to an inner level in order to extend one's current, inadequate understanding' (Pirie \& Kieren, 1994, p. 69).
Pirie and Kieren's (1994) folding back and Tall's (2008) three worlds of mathematics manifest themselves in the mathematics content structure and the questioning approaches used by teachers. In terms of the latter, the issue is how questions that teachers raise can be pitched at a level that encourages the development or formation of the bigger picture of the concept under focus.

\section{Research methodology}

Within the interpretive paradigm, this study pursued the question: where is the bigger picture in the teaching and learning of mathematics? We use pre-existing data collected through pre-observation and post-observation interviews and passive classroom observation by the third author in two different Grade 11 classes taught by two different teachers, Thabiso and Lerato (pseudonyms), at one high school. Pre-observation interviews were conducted to gather information on the teachers' beliefs about the nature of mathematics and how students learn and should be taught, given the current demand for curriculum reforms. Classroom observations, which commenced a week after a pre-observation interview, exposed the teachers' teaching approaches and classroom interactions, which offered an opportunity to establish consistency between the interview responses and the classroom practices. Observations also offered an opportunity to search for alignment between the teachers' teaching philosophy and classroom practice. A post-observation interview sought to get some clarity on issues that emerged during classroom observation. Another set of data was collected through participant observation in the second author's Year 2 University class. In this article, we focus particularly on the teachers' questioning strategies and the approach to content.

We analyse these three different mathematics' teaching cases, guided by Tall's (2008) framework of three worlds of mathematics: the 'conceptual-embodied' world, the 'proceptual-symbolic' world and the 'axiomatic-formal' world. Within this broad framework we acknowledge Pirie and Kieren's (1994, p. 69) notion of folding back towards the attainment of axiomatic-formal world. We trace whether mathematical connections and understandings were encouraged in both content structure and the questioning strategies of the teacher and, lastly, whether those connections were explicit, meaningful, accessible, expandable and transferable. That is, we looked for the bigger picture in both the structure of the content and the questioning strategies used.

\section{Ethical considerations}

Permission was granted by the Education Department, the school and the two teachers who participated. The teachers were made aware of the fact that they were free to voice their opinions, give advice and withdraw, if they felt so inclined. Because the research was not directly focused on the learners, we requested the teacher-participants to explain the research to the learners and their parents, via the school principal. Participation was voluntary and pseudonyms have been 
used to identify the two school teachers (Thabiso and Lerato), ensuring anonymity and confidentiality.

Approval for data collection was obtained from the department in which the study was located, the students and the relevant university structures beyond the department. In both locations, the nature and purpose of the study were declared, inclusive of potential audiences and substantive foci. Erickson (1998, p. 1161) writes: 'consent that is genuinely informed and without coercion reduces the risk of social harm because it affirms the dignity and respects the agency of those who will be involved in the study'. At the university, the students themselves were beneficiaries of the results of this study. They were inducted into the dynamics of what it means to learn mathematics with a view to teaching young learners.

\section{Quality criteria}

It was possible for the three different mathematics' teaching cases to involve prolonged engagement, persistent observation, peer debriefing and member checks with the teachers because the third author was teaching at the same school. With respect to the data collected at the university, the second author was teaching the class and the first author was the internal moderator for the module. We thus had enough opportunity to hear the teachers' voices, which contributed to establishing credibility of this study (Bitsch, 2005; Guba \& Lincoln, 1989). Sufficient descriptive data added to both confirmability and transferability of this study (Guba \& Lincoln, 1989).

\section{Results and discussions}

We organise our results and discussions of the three cases (two cases of high school mathematics teaching and one case from a Year 2 university mathematics education class) below, commencing in each case with a brief biography, followed by two excerpts from the teachers' mathematics lessons, our analysis of the lessons using the identified theoretical framework and a reflection on where the bigger picture is in relation to the teaching and learning of mathematics concepts being addressed.

\section{Case 1: Thabiso}

Thabiso, a male teacher aged 43 years, held a Bachelor in Science Honours degree, majored in Mathematics. He had 18 years of teaching experience and had taught Mathematics in the Further Education and Training band (FET, that is, Grade 10, 11 and 12 classes). He attended Dinaledi Project workshops as part of his professional development. Figure 1 captures two excerpts from his teaching in one of the Grade 11 classes.

In both excerpts, learners were expected to operate in the symbolic world, beginning with processes or actions that are symbolised and coordinated for calculation and manipulation (Tall, 2008). The teacher's questioning strategy encouraged learners to practise the same routine procedures that they would use when dealing with similar problems that do not

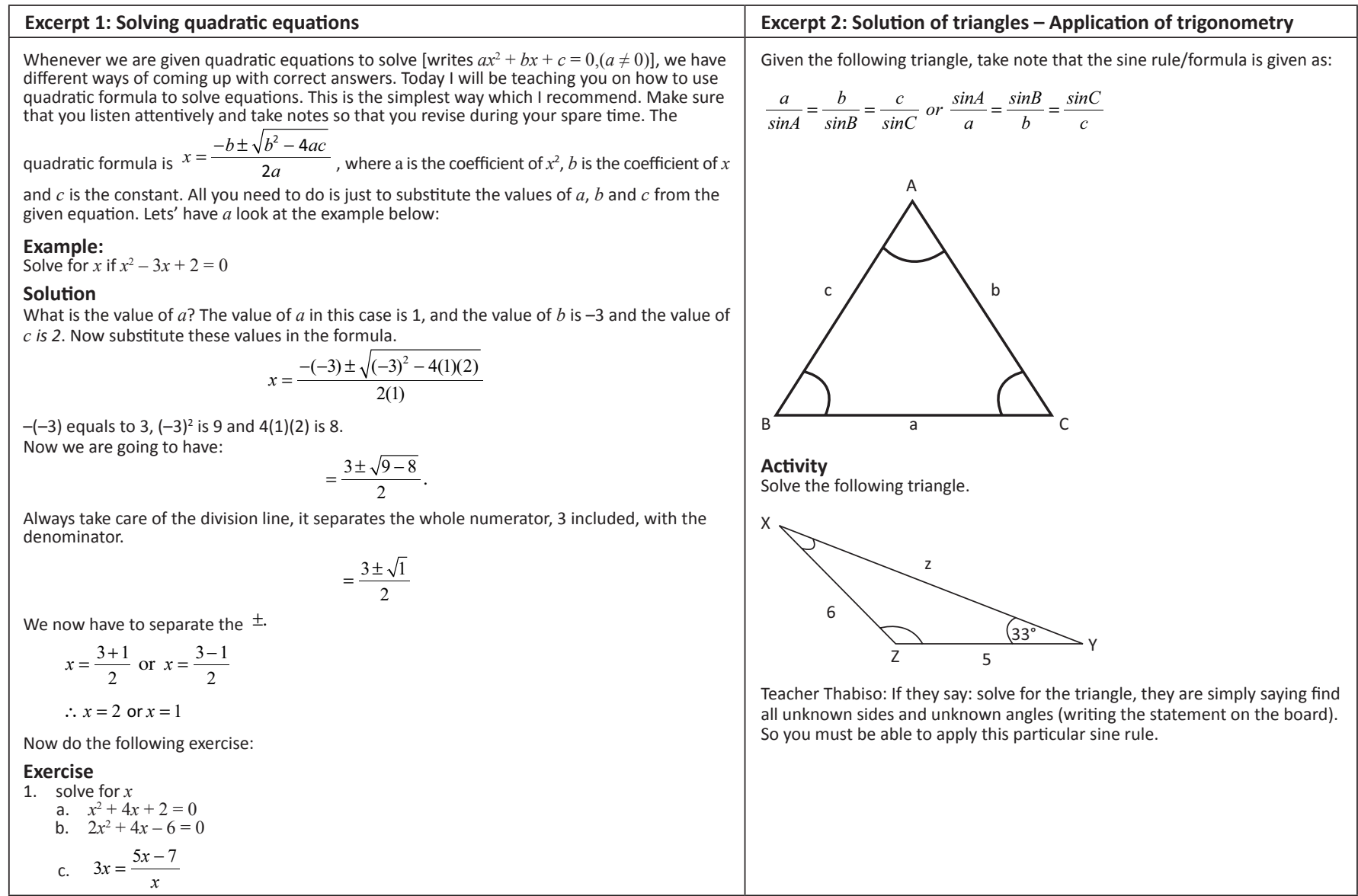

FIGURE 1: Thabiso's two teaching excerpts. 
deviate from the norm, as evidenced in the exercises that followed. The teacher concentrated on a single procedure that could lead to a spectrum of learning outcomes in his class, a proceptual divide (Tall, 2008). Such an approach encourages procedural learning without meaning. It does not provide learners with an opportunity to choose their own strategies, which would necessitate folding back (Pirie \& Kieren, 1994) for them to build deeper understanding.

In excerpt 1 it appears that the teacher was confident that the learners understood what quadratic equations are and how they are derived. For him, it was not necessary to explain to the learners when to use a quadratic formula to solve the quadratic equation. The teacher assumed that learners could work with symbolic representations thus introduced to use the quadratic formula $x=\frac{-b \pm \sqrt{b^{2}-4 a c}}{2 a}$ to solve the equation $x^{2}-3 x+2=0$. The learners were expected to use these met-befores - 'current mental facility based on specific prior experiences of the individual' (Tall, 2008, p. 6) - to identify the value of $a$ as 1 , the value of $b$ as -3 and the value of $c$ as 2. Even if that was the case, the teacher seemed not to trust the learners' met-befores. This became evident when he announced that learners had to listen attentively and should take notes that they could use for revision. After the teacher's explanation on the steps to follow, learners were given an exercise that required them to practise the routine procedure learned from the given example.

Question 1c) deviated a little from the pattern as it required learners to first realise that they needed to simplify the given expression to its standard form before they could follow the routine procedure. It is doubtful whether the learners comprehended why \pm should be separated and what the meaning of the equal sign in the context of quadratics was. It would also be interesting to find out whether learners would know how the values of $x$ relate to the original question and whether they could check solutions meaningfully.

In excerpt 2 the teacher expected the learners to build on their experiences with working with triangles. The learners were expected to recall that they could only use the sine rule if two angles and a side are given or two sides and the non-included angle are given, that is, their met-befores. They had to connect that experience with a concept of the sine rule to find the unknowns. It could have been more empowering if learners were exposed to the given triangle to solve for the unknowns without being reminded of which formula to use. Meaningful learning occurs when learners succeed in choosing effective mathematical strategies to solve given problems.

\section{Where is the bigger picture?}

Reflecting on excerpt 1, we wonder whether learners would know, before even attempting any given quadratic equation to solve, that the equation might have two solutions, or one solution, or perhaps no solution. The bigger picture with regard to quadratic equations lies in their origins. Egyptian, Babylonian and Chinese mathematicians dealt with areas of quadrilaterals and were interested in finding the length and breadth of a rectangle with known area (Gandz, 1940; McMillan, 1984; Yong, 1970). This is generally represented as $a x^{2}+b x=c$ or $x(a x+b)=c$ where $x$ is the breadth, $a x=b$ is the length and $c$ is the area. That is, we are looking for the value of $x$ for which $a x^{2}+b x-c=0$. The challenge that remains is to express the equation as a product so that the null factor law can apply (the null factor law states: if the product of two factors is equal to zero, one or the other, or both, of the factors must be equal to zero. Symbolically it could be written as: if $p q=0$, then $p=0$ or $q=0$ or both $p$ and $q$ are zero). This is the reason why factorisation is the preferred approach to solving quadratic equations. The general formula is ideally used when it becomes difficult to factorise the expression. In fact, the formula itself is a result of using 'completing a square' as a strategy for factorisation. Thabiso's approach did not make that explicit and, as a result, could hinder meaningful learning for most learners and opportunities for the learners to transfer their conceptual understandings. The technical approach was not placed in the appropriate context.

A similar observation is made with regard to excerpt 2 regarding the solution of triangles. The sine rule is one of the many strategies that is used to solve the triangles. Once the rule is derived, it is important that it is adequately analysed to establish the conditions under which it applies and the opportunities it gives us in solving triangles. In other words, in the bigger picture of solution of triangles, when is it appropriate or more ideal to use the sine rule? Determining whether the sine rule is appropriate is more important than its actual application. Thabiso's approach was to ask the learners to simply plug in the values to calculate the missing values. Once again, the technical approach was not placed in the appropriate context within which the sine rule would have been seen as a particular strategy more suitable for a particular situation.

When approached in Thabiso's way, mathematics is viewed as a collection of rules or formulae that learners must memorise, often out of context. Its role as a way of observing and interpreting our daily experiences is stripped away. In his defence, one might argue that at this stage Thabiso was simply helping learners to develop the skill of using the formulae or the rules and that the context would be brought in at a later stage when all different skills had been acquired. This is where we differ from Tall $(2006,2008)$. Our argument is that the bigger picture should always provide the backdrop against which mathematics activities are designed and implemented. The meaningfulness of mathematics cannot be deferred.

\section{Case 2: Lerato}

Lerato, a female teacher aged 51 years, held a Primary Teachers Diploma (PTD), Advanced Certificate (ACE) in Mathematics Education (majored in FET Mathematics teaching). She had 26 years teaching experience and taught mathematics in the FET band (that is, Grade 10, 11 and 12 classes). She attended in-service training workshops at the Mathematics, Science and Technology College (MASTEC) in 
2008 as part of her professional development. Figure 2 captures two excerpts from her teaching in one Grade 11 class.

In both excerpts, learners operated in the symbolic world but were subjected to a different questioning strategy as compared to Thabiso's case. Lerato, like Thabiso, led the learners to perform a procedure to find the correct answer. It is, however, doubtful whether with her questioning, learners would have managed to build up the symbolic mental imagery that is the basis of true understanding (Tarlow, 2014). In other words, although the questions allowed flexibility in terms of searching for solutions, it appeared that, for some learners, encapsulation from process to procept was still problematic (Tall, 2008).

In excerpt 1 , the expected learners' met-befores were to know the standard form of quadratic equations and to factorise. The questions that required learners to share their challenges in factorising, and in making $x$ the subject of the formula, provided opportunities for learners to fold back to their previous experiences (Pirie \& Kieren, 1994). In addition, they offered the teacher some space to give direction by explaining to the learners where they experienced difficulties. This marked Lerato's attempt to employ instructional scaffolding (Vygotsky, 1962), a process that assists growth with regard to understanding of concepts. Another expected met-before was making $x$ the subject of the formula by completing the square. The method of completing the square requires learners to follow specific steps. Thus, those who could respond to question 6 would be those who drew on met-before knowledge and had mastered the routine procedure for this method of completing the square. Although it might have appeared to Lerato that the solution should be easy, for some learners this caused profound difficulties. Once learners realised that they were repeating the same steps for each given quadratic equation, the value of $x$ was then introduced as quadratic formula, which they were expected to use to solve the given exercise.

In excerpt 2, Lerato reminded the learners about the expected met-befores: to use the horizontal reduction and special angles, to locate the given angle and to check the sign of the ratio.
Learners were also expected to know that angles are conventionally measured counter-clockwise from the right hand horizontal axis and that angles measured in a clockwise direction are considered negative. Although an opportunity was provided to fold back to previous experiences, the tasks chosen still did not support learners' mathematising (Tarlow, 2014).

\section{Where is the bigger picture?}

The bigger picture with regard to quadratic equations was outlined in Thabiso's case. In this section the focus is on the questioning strategy that Lerato used to facilitate learning. The questions that Lerato raised were generic and required learners to solve for $x$ in the general quadratic equation. The process led to the derivation of the quadratic formula. The approach had the potential to incorporate the bigger picture inherent in the solution of quadratic equations. This way of solving quadratic equations is just one of many. It is in the context of multiple approaches that the bigger picture becomes clear. If Lerato's questioning strategy focused on a multiplicity of solutions, then the learners would have been in a position to interrogate those solutions with a view to identifying strengths and weaknesses for each. That analysis would have offered them multiple opportunities for folding back (Pirie \& Kieren, 1994).

The question "when can we use the quadratic formula?" captures another aspect of the bigger picture. This prompts the question that, if the general formula method works so well, why would we ever use factoring? If pursued, it would reveal that the bigger picture involves a realisation on the part of learners that general formulas exist only for polynomials with degree less than 5, as proved by the French mathematician Galois (Moore, 1978). What is still not clear is whether the learners would realise that, by finding the values of $x$ for which $a x^{2}+b x-c=0$, they are, in fact, finding the $x$-intercepts of the graph. The learning environment created should be such that it accommodates situations where the quadratic formula also gives learners a zero or a negative inside the square root, thus affording an opportunity to introduce them to use of complex numbers. Operating within a context that allows relating such knowledge simultaneously (even graphing on the $x y$ plane) would provide deep learning,

\begin{tabular}{|c|c|}
\hline Excerpt 1: Solving quadratic equations & Excerpt 2: Solving compound angles \\
\hline $\begin{array}{l}\text { 1. Write down the standard form of quadratic equations? } \\
\text { 2. Factorise the equation you have written in } 1 \text { above? } \\
\text { 3. What are the challenges in factorising the equation? } \\
\text { 4. Make } x \text { the subject of the formula. } \\
\text { 5. Are there any challenges in making } x \text { the subject of the formula? } \\
\text { 6. Let's make } x \text { the subject of the formula by completing the square. } \\
\text { 7. We call that value of } x \text { a quadratic formula. } \\
\text { 8. When can we use a quadratic formula? } \\
\text { 9. Now do the following exercise: } \\
\text { Solve for } \mathbf{x} \\
\text { a. } x^{2}+3 x+2=0 \\
\text { b. } x^{2}+4 x-6=0 \\
\text { c. } 3 x^{2}=3 x-7\end{array}$ & $\begin{array}{l}\text { The reduction formula } \\
\text { 1. Reduce each angle to an acute angle and use special angles where necessary } \\
\text { a) } \sin 150^{\circ} \\
\text { b) } \cos 214^{\circ} \\
\text { c) } \sin 300^{\circ} \\
\text { d) } \tan 120^{\circ} \\
\text { e) } 1-\cos ^{2} 240^{\circ} \\
\text { f) } \cos 330^{\circ} \\
\text { g) } \tan ^{2} 135^{\circ} \\
\text { 2. Evaluate without using a calculator } \\
\text { a) } \sin 150^{\circ}+\tan 330^{\circ} \cdot \cos 30^{\circ} \\
\text { b) } \frac{\sin 150^{\circ}}{\cos 300^{\circ}}-\frac{\tan 300^{\circ}}{\cos 330^{\circ}} \\
\text { Lerato: Remember I have told you that always strive to use the horizontal reduction } \\
\text { to avoid confusion. Remember I have told you that whenever you are given angles, } \\
\text { the first thing to do is to locate the angle that is, determine in which quadrant the } \\
\text { angle lies. Secondly, check whether the ratio is positive or negative. Lastly, check } \\
\text { whether the ratio is going to change or not. }\end{array}$ \\
\hline
\end{tabular}

FIGURE 2: Lerato's two teaching excerpts. 
which reverses the sequence of construction of meaning back and forth between the three worlds of mathematics, as suggested by Tall (2008).

The reduction formulae are meant to take advantage of the circularity of the angles, something that is rarely acknowledged. Lerato's questioning in excerpt 2 prevented the learners from seeing fundamental relationships between lengths, angles and areas of triangles in a broader sense. The use of 'degree' as the unit for measuring angles (the Babylonian astronomers' unit, Emerson, 2005) and use of the unit 'radian', commonly used when graphing trigonometric functions, would remain a mystery to most mathematics learners. It is between the relational understandings of these two units, degree and radian, where the bigger picture in dealing with the reduction formulae resides. If teaching does not expose learners to folding back experiences (Pirie \& Kieren, 1994), the two concepts of plane angle, one treating plane angle as a base quantity and the other defining it as a dimensionless ratio of two lengths, will remain incompatible (Emerson, 2005). An understanding of the fact that trigonometric functions are periodic, that is, repeating over and over again as $\theta$ gets larger or smaller by $2 \pi$, is also necessary to comprehend the bigger picture.

\section{Case 3: Kwena}

The teacher, a male aged 48 years, held a doctoral degree in mathematics education. He majored in Mathematics and Applied Mathematics for his Bachelor of Science (BSc) degree, did a BSc Honours degree in Applied Mathematics and a Higher Education Diploma as a teaching qualification. Figure 3 captures two excerpts from his teaching in a Year 2 class for a Bachelor of Education in Senior Phase and FET teaching programme.

While the learning in the two excerpts started from different worlds, the proceptual-symbolic world in excerpt 1 and the axiomatic-formal world in excerpt 2 (Tall, 2008), it was the questioning strategy employed that supported the learners' mathematical development through a process of mathematising (Tarlow, 2014) and construction of mathematical ideas. The teacher's questions provided a richer learning environment that encouraged taking a multi-procedural approach, which can lead to procedural efficiency (Tall, 2008). Learners were offered some flexibility to investigate possibilities from different entry points. It is doubtful whether all the learners managed to transcend beyond the process into procept (Tall, 2008). A possibility remains that some learners stayed stuck in either the symbolic or the formal world, with emphasis on the logic and with a less conceptual insight.

In excerpt 1, just like in Thabiso's case, the learning was approached from the point of view of orientating learners on one procedure to solve a system of linear equations represented by $A X=B$, where $A$ and $B$ are matrices and $X$ is a column matrix of unknowns. It was an entry into the investigation which allowed more than one possible strategy, with no predictable procedure to find a solution. In excerpt 2 , in order to respond to the first two questions, confirming limits of functions using the $\varepsilon$ and $\delta$ methods and stating the mean value theorem and providing its detailed proof, required that connections be made within the formal world. The subsequent questions in both excerpts added a different learning flavour, making provision for learners' self-questioning. As learners searched for efficient solutions and interpreted and constructed the meaning of the concepts at hand, they were encouraged to formulate the critical questions that they would ask their teacher and those that they would pose to the whole class. Unlike Lerato's approach, the instructional scaffolding (Vygotsky, 1962) was approached from a different angle. The approach involved learner interactions in different forms that did not necessarily progress sequentially, including student-material interaction, student-student interaction, student-teacher interaction and whole-class interaction. Evident was the dialogical and interactional nature of scaffolded instruction that encouraged a nonthreatening participation in a shared community of practice (Van Lier, 2004).

\section{Where is the bigger picture?}

Matrices emanated from the study of solutions of a system of linear equations. The idea was to find different strategies that could be used to solve the unknowns efficiently and reliably. However, as mathematical objects, their properties are also

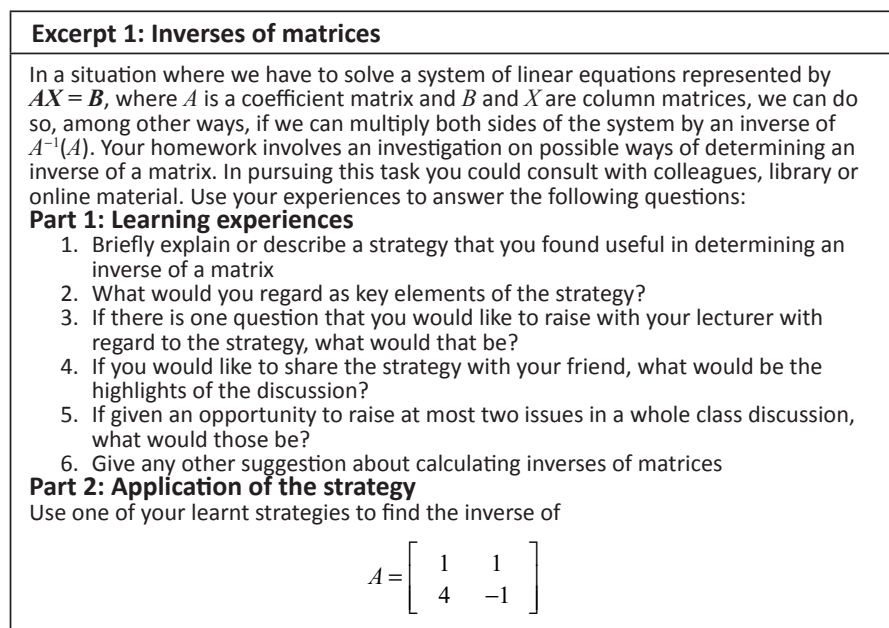

FIGURE 3: Kwena's two teaching excerpts.

\section{Excerpt 2: The mean value theorem}

Learning outcome 1: Limits and continuity

The student is able to describe, analyse, represent and provide theoretical argument The student is able to describe, analyse, repres
for limits and continuity of different functions.

The mean value theorem and its applications
The

1 . First describe in detail using your own words the process of confirming limits of functions using the $\varepsilon$ and $\delta$ methods.

2. Clearly state the mean value theorem and provide its detailed proof. Support your proof with clear arguments/reasons.

3. Show different types of situations or problems in which it is necessary to apply the mean value theorem to confirm limits. Justify why it is necessary to apply the theorem.

4. Identify and solve three problems involving limits of different forms of functions. In the three problems it must be necessary to apply the mean value theorem.

5. As a team you should have asked yourself lots of questions that allowed you to carry the task forward. Give at least two such questions that you regard as critical to what you have done.

6. Having gone through the task, if you had an opportunity to ask me one key question with regard to the mean value theorem, then what would that be?

7. At this stage, if you were to present your task to other students in a whole class discussion setting, then what will be your main emphasis? Work in groups of at most 4 
amenable to the four mathematical operations addition, subtraction, division and multiplication. At the core of all these operations, is the solution of the matrix equation $A X=B$, where $A$ is the coefficient matrix and $X$ and $B$ are column matrices. Ideally, we should always ask how each skill that we acquire, or each strategy that we develop, assists us in the solution of the matrix equation above. Like with all other areas of mathematics, each skill or strategy has its own strengths and weaknesses. Hence, the end is not the mastering of the strategy itself, but whether it presents itself as the most efficient solution at that particular time. That is, an analysis of the strategy should always be integral to mathematics learning activities. This way, each learning opportunity enhances Pirie and Kieren's (1994) folding back and collecting, while also enriching Tall's (2008) proceptual stage of mathematising.

The same scenario applies to the limits of functions. Given the function $f(x)$ we are to establish whether $\lim f(x)=l$ exists. A variety of skills and strategies are required to determine the limits of functions. Strategies used include numerical approaches, graphical approaches and symbolic approaches. The use of tools, such as theorems, constitutes a strategy that uses a theoretical approach. The learning or development of such tools away from their intended purposes works against the development of the bigger picture. But even more challenging is the learning of skills and strategies without interrogating their relative efficiencies in addressing the problem at hand. The exclusion of this aspect makes it a challenge to transcend from multiple strategies to the proceptual stage.

Both excerpts require students to analyse the strategies used in resolving the problems at hand. While the first excerpt is wide open in terms of the strategies around the bigger picture, the second excerpt is anchored around a particular strategy: the mean value theorem. This makes the first excerpt relatively stronger in addressing the bigger picture. On the other side, the application is closed in the first excerpt, as a particular scenario is given, whereas it is open in the second excerpt, as students are expected to come up with their own problems. This makes the second excerpt relatively stronger with regard to the bigger picture. The insistence on reflections on own experiences and the generation of reflective questions in both excerpts makes the realisation of the bigger picture in both cases more likely. The approach in both cases, if well developed, has the potential to contribute to an integrated development of the bigger picture with regard to the concepts at hand.

\section{Conclusion}

In this article we pursued the question: where is the bigger picture in the teaching and learning of mathematics? We used three teaching cases to analyse the presence or absence of the bigger picture, especially, in the teachers' questioning strategies and their approach to content. In both Tall's (2008) three worlds of mathematics and Pirie and Kieren's (1994) growth in mathematics understanding, the bigger picture of mathematics is captured in the process of growth of a mathematical idea or concept. Almost all mathematics ideas evolve from a primitive or concrete stage through to their axiomatic formal stage. However, it was Pirie and Kieren's folding back that was found to be more practical at the teacherlearner interface. In that context, our argument is that the bigger picture of the idea at hand should influence how the lesson unfolds. The content structure and the nature of the questions the teacher raises should reflect the way the bigger picture is anchored in the teaching and learning of mathematics. In that way mathematics is meaningful, accessible, expandable and transferable. The bigger picture should always provide the backdrop against which mathematics activities are designed and implemented. In that way the meaningfulness of mathematics cannot be deferred.

In the three teaching cases that we have used in the study, we found that all the topics covered had potential for the incorporation of a bigger picture of mathematics. However, the analysis of the content and questioning strategies in those lessons revealed that either the influence of a bigger picture was non-existent or it had minimal influence. In the case of Thabiso's approach, the influence of the bigger picture was non-existent on both the content structure and the questioning strategy with regard to quadratic equations and the solution of triangles. In both Lerato's and Kwena's cases, engagement with the content was framed by their questioning strategies. In Lerato's case, the questioning strategy had glimpses of influences of the bigger picture of quadratic equations and that of the solution of trigonometric equations. In Kwena's case, the questioning strategy revealed a concerted effort to incorporate the bigger picture of matrices and that of limits in the lessons. However, a lot is still needed to improve on that practice.

Generally, all three teachers can benefit from exposure to the influence of the bigger picture in the teaching and learning of mathematics. Both Tall's (2008 \& 2011) and Pirie and Kieren's (1994) ideas can be used to interrogate different topics in mathematics in order to show specific ways in which the bigger picture can be used in classroom lessons. Hashemi, Abu, Kashefi, Mokhtar and Rahimi (2015) used Tall's ideas to improve the teaching of derivatives and integrals. Furthermore, the non-incorporation of the bigger picture cannot solely be blamed on the teachers. The assessment regime in the system of education, the learning support materials and the training of teachers need to incorporate the bigger mathematics picture in their orientations.

\section{Acknowledgements Competing interests}

The authors declare that they have no financial or personal relationships that may have inappropriately influenced them in writing this article.

\section{Authors' contributions}

S.M. was the project leader and moderator of K. Masha's assessment instruments. K. Masha facilitated lessons in the Year 2 university class and captured data from that activity. 
K. Maphutha collected data from the two teachers' mathematics classes and assisted in peer debriefing and member-checks with the teachers involved. S.M. and K. Masha conceptualised the article and thereafter S.M. produced the first draft. The two then proceeded to work on the final draft.

\section{References}

Bitsch, V. (2005). Qualitative research: A grounded theory example and evaluation criteria. Journal of Agribusiness, 23(1), 75-91.

Charles, R.I. (2005). Big ideas and understandings as the foundation for elementary and middle school mathematics. Journal of Mathematics Education Leadership, $7(3)$ 9-24.

Davis, B. (1997). Listening for differences: An evolving conception of mathematics teaching. Journal for Research in Mathematics Education, 28(3), 355-376.

Emerson, W.H. (2005). Differing angles on angle. Metrologia, 42, 23-26.

Erickson, F. (1998). Qualitative research methods for science education. In B.F. Fraser, \& K.G. Tobin (Eds.), International handbook of science education (pp. 1155-1173). Dordrecht: Kluwer.

Gandz, S. (1940). Studies in Babylonian mathematics III: Isoperimetric problems and the origin of the quadratic equations. Isis, 32(1), 103-115. Available from http:// www.jstor.org/stable/226057

Gray, E.M., Pitta, D., Pinto, M.M.F., \& Tall, D.O. (1999). Knowledge construction and diverging thinking in elementary and advanced mathematics. Educational Studies in Mathematics, 38(1-3), 111-133.

Guba, E.G., \& Lincoln, Y.S. (1989). Fourth generation evaluation. Newbury Park, CA: Sage Publications.

Hashemi, N., Abu, M.S., Kashefi, H., Mokhtar, M., \& Rahimi, K. (2015). Designin learning strategy to improve undergraduate students' problem solving in derivatives and integrals: A conceptual framework. Eurasia Journal of Mathematics, Science \& Technology Education, 11(2), 227-238.

Hiebert, J., \& Grouws, D.A. (2007). The effects of classroom mathematics teaching on students' learning. Second handbook of research on mathematics teaching and learning, 1, 371-404.

McMillan, R.D. (1984). Babylonian quadratics. The Mathematics Teacher, 77(1) 63-65. Available from http://www.jstor.org/stable/27963851

Moore, F.R. (1978). An introduction to the mathematics of digital signal processing Part 1: Algebra, trigonometry, and the most beautiful formula in mathematics. Computer Music Journal, 2(1), 38-47.

Pirie, S., \& Kieren, T. (1994). Growth in mathematical understanding: How can we characterise it and how can we represent it? Educational Studies in Mathematics, 26, 165-190.

Tall, D. (2006, December). Setting lesson study within a long-term framework for learning. Plenary presentation at the APEC-Tsukuba International Conference. Tokyo: Institute for International Cooperation. Available from http://homepages. warwick.ac.uk/staff/David.Tall/pdfs/dot2007e-apec-thailand.pdf

Tall, D. (2008). The transition to formal thinking in mathematics. Mathematics Education Research Journal, 20(2), 5-24.

Tall, D. (2011). Looking for the bigger picture. For the Learning of Mathematics, 31(2), $17-18$.

Tarlow, L.D. (2014). Assessing teacher change in facilitating mathematizing in urban middle schools: Results of an effective professional development program. Current Issues in Middle Level Education, 19(2), 9-12.

Van Lier, L. (2004). The ecology and semiotics of language learning. Dordrecht: Kluwer Academic.

Vygotsky, L.S. (1962). Thought and language. Cambridge, MA: MIT Press.

Wilson, P.S., Cooney, T.J., \& Stinson, D.W. (2005). What constitutes good mathematics teaching and how it develops? Nine high school teachers' perspectives. Journal of Mathematics Teacher Education, 8, 83-111.

Yong, L.L. (1970). The geometrical basis of the ancient Chinese square-root method. Isis, 61(1), 92-102. Available from http://www.jstor.org/stable/229151 